Article type : Original Article

Running head recto: $U V-C$ seed treatments for disease control

\title{
Hormetic UV-C seed treatments for the control of tomato diseases
}

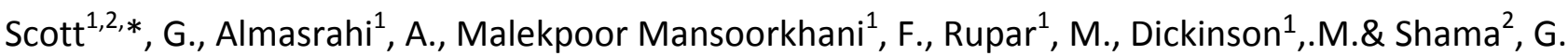

1 Division of Plant and Crop Sciences, University of Nottingham, Sutton Bonington Campus,

Sutton Bonington, Leicestershire, LE12 5RD, UK

2 Department of Chemical Engineering, Loughborough University, Loughborough, Leicestershire, LE11 3TU, UK

*Corresponding author: G.Scott@lboro.ac.uk

\begin{abstract}
Hormesis is a dose response phenomenon in which low, non-damaging doses of a stressor bring about a positive response in the organism undergoing treatment. Evidence is provided here that hormetic UV-C treatments of tomato seed can control disease caused by Botrytis cinerea, Fusarium oxysporum f.sp. lycopersici (FOL) and f.sp. radicis-lycopersici (FORL) on tomato (Solanum lycopersicum). Treating seeds with a $4 \mathrm{~kJ} / \mathrm{m}^{2}$ dose of UV-C significantly reduced both the disease incidence and progression of $B$. cinerea, with approximately $10 \%$ This article has been accepted for publication and undergone full peer review but has not been through the copyediting, typesetting, pagination and proofreading process, which may lead to differences between this version and the Version of Record. Please cite this article as doi: 10.1111/ppa.12987

This article is protected by copyright. All rights reserved.
\end{abstract}


reductions in both on the cv. Shirley. Disease severity assays for FOL and FORL on cv. Moneymaker showed dose-dependent responses: UV-C treatments of 4 and $6 \mathrm{~kJ} / \mathrm{m}^{2}$ significantly reduced the disease severity scores of $\mathrm{FOL}$, whilst only the $6 \mathrm{~kJ} / \mathrm{m}^{2}$ showed significant reductions for FORL. To determine the effects of treatment on germination and seedling growth, UV-C doses of 4,8 and $12 \mathrm{~kJ} / \mathrm{m}^{2}$ were performed on the $\mathrm{cV}$. Shirley. No negative impacts on germination or seedling growth were observed for any of the treatments. The $8 \mathrm{~kJ} / \mathrm{m}^{2}$ treatment, however, showed significant biostimulation with increases in seedling, root and hypocotyl dry weight at $11.4,23.1$, and $12.0 \%$, respectively, when compared to the control. Furthermore, significant increases in the root-mass fraction (10.6\%) and root:shoot ratio (13.1\%) along with a decrease in shoot-mass fraction (2.0\%) indicates that the $8 \mathrm{~kJ} / \mathrm{m}^{2}$ treatment stimulated root growth to the greatest extent. There was no effect on hypocotyl and primary root length or the number of lateral roots indicating no adverse effects to basic root architecture or seedling growth.

Keywords: UV-C hormesis; Solanum lycopersicum; seed treatments; disease control; biostimulation

\section{Introduction}

Tomato is a globally important crop with a gross production value of $\$$ US 92,490 million globally in 2014 (FAO, 2018). Plant pathogens can cause devastating losses to tomato crops. For example, Botrytis cinerea and Fusarium oxysporum f.sp. lycopersici have been reported to cause crop losses of up to 70 and 80\%, respectively (Borges et al., 2014 \& Nirmaladevi et 
al., 2016). With the introduction of EU legislation on the sustainable use of plant protection products and the emergence of fungicide resistance, limited disease control options are available to commercial producers. For instance, in the UK there is not a single approved fungicide against Botrytis cinerea for which resistance has not been observed on tomato (McPhearson, 2015). There is, therefore, an urgent need to identify effective alternatives to chemical control. Hormetic UV-C treatments may constitute one such alternative.

The portion of the electromagnetic spectrum between 100 and $280 \mathrm{~nm}$ is referred to as the UV-C region. Due to its germicidal action, high-dose UV-C treatments are used in the sterilisation of the surfaces of solids, liquids and gases. Such treatments, however, are not the focus of this study. UV-C hormesis is a phenomenon where low-dose, non-damaging UVC exposures induce beneficial responses in the organism undergoing treatment. In 1987 the first observations of UV-C hormesis in fresh produce were published (Lu et al., 1987). Hormetic UV-C treatments have now been shown to be effective on a wide range of fresh produce including both climacteric and non-climacteric fruit, tubers, salads and brassicas (Ranganna et al., 1997; D'Hallewin et al., 1999, Costa et al., 2006; Pongprasert et al., 2011 \& Kasim \& Kasim, 2012). The benefits of UV-C hormesis on fresh produce include disease resistance, delayed chlorophyll degradation and improved nutritional content; reviewed in depth by Shama \& Alderson (2005), Ribeiro et al. (2012), Turtoi (2013) and Urban et al. (2016). More recently, UV-C treatments directed at seeds have shown to induce hormesis (Brown et al., 2001). To date, however, only a small number of studies on the effects of UVC seed treatment on disease resistance and plant physiology have been published. Two publications have reported that plants grown from UV-C-treated seed exhibit reduced levels 
of disease. Firstly, Brown et al. (2001) showed that a treatment of $3.6 \mathrm{~kJ} / \mathrm{m}^{2}$ reduced the incidence of Xanthomonas campestris pv. campestris by $75 \%$ on cabbage (Brassica oleracea). More recently, Siddiqui et al. (2011) reported reductions of up to $88 \%$ in the incidence of disease caused by Fusarium spp., Rhizoctonia solani and Macrophomina phaseolina on mung bean (Vigna radiata) and groundnut (Arachis hypogaea). The optimal UV-C dosage for disease resistance was shown to be dependent on the crop and pathogen undergoing investigation.

Further benefits of UV-C seed treatment include increased dry mass, increased germination rate, improved crop colour, delayed maturity, increased seedling vigour index and an increased number of root nodules (Brown et al., 2001; Siddiqui et al., 2011; Hamid \& Javvaid 2011; Neelamegam \& Sutha 2015). Additionally, lettuce (Lactuca sativa) and green bean (Phaseolus vulgaris) plants grown from UV-C-treated seed have shown an increased tolerance to salt stress (Aboul Fotouh et al., 2014; Ouhibi et al., 2014;).

The aim of this study was to explore the effect of a range of UV-C treatments on disease susceptibility to the necrotrophic tomato pathogens Botrytis cinerea, Fusarium oxysporum f.sp. lycopersici (FOL) and radicis-lycopersici (FORL). In addition, investigations into how UVC seed treatment effects germination and seedling growth were conducted.

This article is protected by copyright. All rights reserved. 


\section{Materials and methods}

\subsection{Seeds, seed storage and UV-C treatment}

Seeds of the tomato cvs. Shirley and Moneymaker were purchased from Sow Seeds and Johnsons' Seeds, respectively. Seeds were stored at $6^{\circ} \mathrm{C}$ at a relative humidity of $<50 \%$. UVC treatments were performed with a U-shaped amalgam UV-C source (UVI 120 U 2 G11 C P 15/469) with peak emission at 254 nm, obtained from Dr Hőnle AG, Gräfelfing, Germany. The source was housed within an anodised aluminium parabolic reflector. Seeds were treated at an intensity of $20 \mathrm{~W} \mathrm{~m}^{-2}$ and immediately stored in the dark at $21^{\circ} \mathrm{C}$ for $5 \mathrm{~d}$ following the procedures of Brown et al. (2001). UV-C intensity was measured using a radiometer (Model UVX, UVP Instruments) fitted with a $254 \mathrm{~nm}$ sensor.

\subsection{Plant husbandry}

Seeds were planted in 1 litre pots of Levington ${ }^{\mathrm{TM}} \mathrm{M} 3$ compost and grown in a temperature controlled, ventilated glasshouse at the University of Nottingham. Lighting by the means of 400 W HPS SON-T lighting (Phillips) was used on a 16/8 h photoperiod. Day and night temperatures were $24 / 18 \pm 2^{\circ} \mathrm{C}$.

\subsection{Pathogen maintenance, inoculum preparation and inoculation}

Botrytis cinerea and FORL cultures were supplied from the University of Nottingham's fungal collection. The FOL culture was provided by Alison Jackson (The University of Warwick).

Cultures were grown on potato dextrose agar (Sigma-Aldrich) supplemented with penicillin G sodium salt (Sigma-Aldrich) at $33 \mathrm{mg} / \mathrm{L}$ and streptomycin sulphate salt (Sigma-Aldrich) at 
$133 \mathrm{mg} / \mathrm{l}$. Botrytis cinerea cultures were grown in ambient light at room temperature and FOL and FORL cultures were kept in the dark at $27^{\circ} \mathrm{C}$.

For $B$. cinerea inoculations, plants were grown under glass to the first signs of flowering (56 w). Prior to inoculation, plants were moved to a controlled environment using 400 W HPS SON-T lighting (Phillips) with a $16 / 8 \mathrm{~h}$ photoperiod at $21^{\circ} \mathrm{C}$. Stem inoculations were then performed by removing a leaf and leaving a $10 \mathrm{~mm}$ petiole stub protruding from the stem; replicating a broken petiole. Petiole stubs were then inoculated with $10 \mu \mathrm{l}$ of $5 \times 10^{6}$ spores $/ \mathrm{ml}$ amended with $40 \%$ red grape juice. Calibrated spore solutions were prepared from 10 - 14 d old cultures following the procedures described by Scott et al. (2017). Three technical repeats were performed on each plant at true leaves 3,4 and 5 .

Stem lesion length was measured with Vernier callipers at 4 and $6 \mathrm{~d}$ post inoculation (DPI) and used to calculate the area underneath the disease progression curve (Equation 1).

$$
\mathrm{AUDPC}=\sum_{i=1}^{n} \frac{y_{i}+y_{i+1}}{2}\left(t_{i+1}-t_{i}\right)
$$

Eq. 1. Area Underneath the Disease Progression Curve formula where $n=$ total number of observations per inoculation point, $i=$ observation, $y=$ disease score and $t=$ time (Jeger and Viljanen-Rollinson, 2001).

This article is protected by copyright. All rights reserved. 
FOL and FORL inoculations were performed on cv. Moneymaker seedlings 22 days after planting. A calibrated spore solution of $1 \times 10^{6}$ spores per $\mathrm{ml}$ was made from $7 \mathrm{~d}$ old cultures. The compost was moistened, and seedlings were carefully removed. Roots were gently rubbed with Celite ${ }^{\circledR}$ (Sigma Aldrich) and incubated in $30 \mathrm{ml}$ of spore solution for $2 \mathrm{~h}$. Plants were re-potted and not watered until the following day. Disease severity was scored at 30 days post-inoculation following Reis \& Boiteux (2007) and Parke \& Grau (1993) for FOL and FORL, respectively. Two plants from each treatment group were mock inoculated and used as a control for the inoculation procedures.

\subsection{Monitoring seed germination and seedling growth}

Seedling germination and growth measurements were carried out according to the protocols of Ron et al. (2013). Following UV-C treatment, seeds were sterilised to prevent the growth of naturally occurring microflora. Seeds were washed in $70 \%$ ethanol for $2 \mathrm{~min}$ and $3 \%$ sodium hypochlorite (Sigma-Aldrich) for $20 \mathrm{~min}$ followed by 3 washes in sterile distilled water. Seeds were plated in a randomised block design on $120 \mathrm{~mm}$ square Petri dishes filled with $50 \mathrm{ml}$ of Murashige and Skoog medium at $4.3 \mathrm{~g} / \mathrm{l}(\mathrm{pH} \mathrm{5.8)}$ amended with 0.8\% agar technical No.3 (Oxoid); seven seeds were used per plate. Plates were sealed with surgical tape $(3 \mathrm{M})$ and stored vertically in a controlled environment with a $16 \mathrm{~h}$ photoperiod at $22^{\circ} \mathrm{C}$. Germination was monitored for $7 \mathrm{~d}$ following plating.

Primary root and hypocotyl lengths were measured at 2 and $5 \mathrm{~d}$ post germination (DPG) with ImageJ. When individual seedlings reached 5 DPG they were dissected and dried for 24 h at $50^{\circ} \mathrm{C}$ to measure dry mass of the roots, hypocotyl and cotyledon. To measure 
germination, total germination percentage, germination index (Equation 2), $T_{50}$ (Equation 3) and Z-index (Equation 4) were used. For measuring growth, root and stem mass fraction, root:shoot ratio and seedling vigour index II were calculated (Table 1).

$$
G I=\left(7 \times n_{1}\right)+\left(6 \times \mathrm{n}_{2}\right)+\ldots+\left(1 \times \mathrm{n}_{7}\right)
$$

Eq. 2. Germination index (GI), where $n_{1}, n_{2}, \ldots, n_{7}$ are the number of germinated seeds on the first, second and subsequent days until the $7^{\text {th }} ; 7,6, \ldots, 1$ are the weights given to the seeds germinated on the first, second and $7^{\text {th }}$ days, respectively (Walker-Simmons, 1987).

$$
T_{50}=t_{i}+\frac{(N+1) / 2-n_{i}}{n_{j}-n_{i}} \times\left(t_{j}-t_{i}\right)
$$

Eq. 3. The time to reach $50 \%$ germination $\left(T_{50}\right)$ for the total number of seeds planted. $N$ is the final number of seeds that have germinated, $n_{i}$ and $n_{j}$ are the total number of seeds germinated at adjacent time points $t_{i}$ and $t_{j}$ where $n_{i}<(N+1) / 2<n_{\mathrm{j}}$ (Coolbear et al., 1984).

$$
Z=\sum \frac{C n_{i, 2}}{N} \text { where } C n_{i, 2}=\frac{n_{i}\left(n_{i}-1\right)}{2} \text { and } N=\frac{\sum n_{i}\left(n_{i}-1\right)}{2}
$$

Eq. 4. Synchrony of germination (Z-index) where $n_{i}$ is the number of seeds germinated during the ith time (Ranal et al., 2009).

This article is protected by copyright. All rights reserved. 


\subsection{Experimental design and data analysis}

For all experiments, data from each independent replicate experiment was combined prior to statistical analysis. For disease control experiments, UV-C doses of 2,4 and $6 \mathrm{~kJ} / \mathrm{m}^{2}$ were applied alongside an untreated control. Three independent replicate experiments with a total of 24 biological and 72 technical repeats per treatment group were performed for experiments concerned with the control of $B$. cinerea. Due to inter-experimental variation in the susceptibility to B. cinerea, factor correction was performed following Ruijter et al. (2006). For the FOL and FORL disease control study, two independent experimental replicates were performed with a total of 12 biological repeats. A randomised experimental design was used in both B. cinerea and F. oxysporum studies. Data were analysed in SPSS (IBM) by Kruskal Wallis and Dunn's post-hoc test with Bonferroni correction.

For experiments in which the effect of UV-C seed treatment on germination and seedling growth were monitored, doses of $0,4,8$ and $12 \mathrm{~kJ} / \mathrm{m}^{2}$ were applied. Three independent replicate experiments were performed, with a total of 63 biological repeats per treatment group. Data were analysed by one-way ANOVA with Tukey's post-hoc test. Where the homogeneity of variances assumption could not be met, Welch's robust ANOVA was performed followed by the Games-Howell post-hoc test. Statistical significance is defined as $p<0.05$ for all experiments.

This article is protected by copyright. All rights reserved. 


\section{Results}

\subsection{Disease control}

For B. cinerea disease control assays, plants grown from seed treated with a dose $4 \mathrm{~kJ} / \mathrm{m}^{2}$ showed a statistically significant decrease in disease incidence when compared to the control and plants grown from seed treated with a $6 \mathrm{~kJ} / \mathrm{m}^{2}$ dose at $10.3 \%$ for both (Figure 1a). The $4 \mathrm{~kJ} / \mathrm{m}^{2}$ treatment also showed a significant reduction in the median disease progression (11.4\%) in comparison to the control (Figure 1b).

Significant reductions in disease severity were observed for plants grown from UV-C-treated seed when inoculated with FOL or FORL (Figure 2). For FOL, both $4 \mathrm{~kJ} / \mathrm{m}^{2}$ and $6 \mathrm{~kJ} / \mathrm{m}^{2}$ doses significantly decreased disease severity with median scores dropping to 2.5 and 2.0 from 3.5 (control). A $6 \mathrm{~kJ} / \mathrm{m}^{2}$ dose significantly reduced FORL severity with a median of 1.5 compared to the control at 2.0 (Figure $2 \mathrm{~b}$ ). All mock inoculated plants were free from visible symptoms.

\subsection{Effects on seedling growth}

No significant differences in germination metrics were observed following treatment (Figure 3 and Table 2). Seeds treated with an $8 \mathrm{~kJ} / \mathrm{m}^{2}$ dose, however, showed slight reductions in the time to first germination event and time to $50 \%$ germination $\left(T_{50}\right)$, while increases to the cumulative germination percentage, germination index, seedling vigour index-II and synchronicity of germination (Z-index) were observed when compared to the control (Table 2).

This article is protected by copyright. All rights reserved. 
At 5 DPG primary root and hypocotyl lengths were measured, seedlings were dissected, dried and weighed to determine the effect of treatment on the growth of major plant organs. Significant increases were observed for the total seedling, shoot, hypocotyl and root dry mass for the $8 \mathrm{~kJ} / \mathrm{m}^{2}$ treatment in comparison to the control with increases of 11.4\%, 12.0\%, 9.2\% and 23.1\%, respectively (Figure 4a, 4c, 4d and 4e). The cotyledon dry mass increased by $8 \%$ for the $8 \mathrm{~kJ} / \mathrm{m}^{2}$ treatment, in comparison to the control (Figure $4 \mathrm{~b}$ ). The difference, however, was not statistically significant.

No statistically significant differences in organ length were observed for any treatments (Figure 5). The number of lateral roots at was not affected by any of the treatments, although small increases were observed for the 4,8 and $12 \mathrm{~kJ} / \mathrm{m}^{2}$ treatments (Figure $5 \mathrm{~d}$ ). Finally, a statistically significant increase in mean root-mass fraction (10.6\%) and root:shoot ratio (13.1\%) and a decrease in stem-mass fraction (2.0\%) was observed for the $8 \mathrm{~kJ} / \mathrm{m}^{2}$ treatment in comparison to the control (Figure 6).

\section{Discussion}

Tomato seeds treated with UV-C doses of either 2,4 or $6 \mathrm{~kJ} / \mathrm{m}^{2}$ were used to grow plants for disease control assays. $B$. cinerea inoculations were performed on broken petioles; a common site of natural inoculation in commercial glasshouses (Beyers et al., 2014). Inoculations were performed during flowering as disease susceptibility increases during anthesis (Borges et al., 2014). A $4 \mathrm{~kJ} / \mathrm{m}^{2}$ dose showed significant reductions in the incidence

This article is protected by copyright. All rights reserved. 
$(10.3 \%)$ and progression (11.4\%) of $B$. cinerea. Furthermore, our data indicates that disease control may have good longevity as plants were inoculated 5 to 6 weeks post planting.

Similar patterns in disease severity score were observed for FOL and FORL inoculations, with a reduction in high scoring plants as dose increased. FOL disease severity was significantly reduced with 4 and $6 \mathrm{~kJ} / \mathrm{m}^{2}$ treatments, while only the $6 \mathrm{~kJ} / \mathrm{m}^{2}$ treatment significantly reduced FORL disease severity.

These are the first observations of UV-C seed treatment disease control on tomato and indicate that UV-C seed treatments may provide versatile and residue-free disease control method. Furthermore, we have shown that UV-C seed treatments can successfully control different pathogens on contrasting cultivars at differing developmental stages.

Our findings are in accordance with Brown et al., (2001) \& Siddiqui et al., (2011) who reported reduced incidence of $X$. campestris pv campestris on cabbage and Fusarium spp., R. solani and M. phaseolina on mung bean and groundnut following UV-C seed treatment. We have shown for the first time, however, that UV-C seed treatments can also reduce disease progression following a successful inoculation event.

This article is protected by copyright. All rights reserved. 
With high levels of fungicide resistance and a reduction in the number of authorised actives, UV-C seed treatment may provide a valuable addition to integrated disease management strategies. Commercial trials using naturally occurring disease, however, are required to determine the efficacy and the cost-benefit analysis of implementing UV-C seed treatments.

The mechanisms controlling UV-C seed treatment's disease control is unknown. Induced resistance, however, is a likely player and has been shown against $B$. cinerea following UV-C treatment of tomato fruit (Charles et al., 2008a \& Scott et al., 2018). Resistance was underpinned by the constitutive upregulation of genes encoding pathogenesis related proteins (Glu-B, Chi-9 and P4) and increased concentration of phytoalexin rishitin (Charles et al., 2008a \& Scott et al., 2018). Gene priming may also play a role facilitating a rapid response to the first plant-pathogen interaction as a priming related expression profile was identified for PAL following inoculation (Scott et al., 2018).

To determine the effect of UV-C treatment on seedling growth, a $4 \mathrm{~kJ} / \mathrm{m}^{2}$ treatment was used alongside doses of 8 and $12 \mathrm{~kJ} / \mathrm{m}^{2}$ to ascertain whether higher doses of UV-C have detrimental effects on plant growth. No negative effects were observed on seedling germination, growth or basic root architecture for any treatment.

The $8 \mathrm{~kJ} / \mathrm{m}^{2}$ treatment, however, showed statistically significant biostimulation of seedling growth with an $11.4 \%$ increase in total seedling mass. Biostimulation of growth has also been observed by Brown et al., (2001); Siddiqui et al., (2011); Hamid \& Javvaid, (2011) \& 
Neelamegam \& Sutha, (2015). Here, root mass was stimulated to the greatest extent (23.1\%), while no differences in primary root length or lateral root number were observed. This may indicate an increase in root volume and a greater efficiency in nutrient and water acquisition, further investigations are required to establish this with certainty.

Biostimulation of hypocotyl and shoot growth increased dry mass by $9.1 \%$ and $12.0 \%$, respectively. No changes to hypocotyl length were observed. To elucidate the physiological changes underpinning biostimulation, future investigations should focus on organ-specific cellular volume, structure and organisation. Potential alterations to the cell wall such as lignin and suberin deposition should also be explored; as reported by Charles et al. (2008b) following UV-C treatment of tomato fruit.

Although significant increases in both root and shoot dry mass were observed for the 8 $\mathrm{kJ} / \mathrm{m}^{2}$ treatment, significant increases in root mass fraction and root:shoot ratio and a decrease in stem mass fraction were also observed (Figure 6c). This suggests that UV-C seed treatment induces systemic biostimulation that is weighted towards the roots; inferring either that photoassimilates are being directed favourably towards the root system or that it induces a perturbation in hormonal balance controlling plant development. This observation may be expected as environmental stresses have been shown to increase root:shoot ratio (Eghball and Maranville, 1993).

The $8 \mathrm{~kJ} / \mathrm{m}^{2} \mathrm{UV}-\mathrm{C}$ treatment may also lead to the biostimulation of germination as positive effects were observed on total germination \%, germination index, synchronicity ( $Z$ index), seedling vigour index (II) and $T_{50}$. Further investigation is required to determine whether 
these effects are significant. Increases in the total germination percentage of UV-C treated seed, however, have been reported by Siddiqui et al. (2011), Hamid \& Javvaid (2011) and Neelamegam \& Sutha (2015).

To conclude, this study has identified that UV-C seed treatments are an effective disease control method against both foliar and root pathogens of tomato. Specific UV-C doses are required to elicit biostimulation or disease control and for different pathogens on different cultivars. Further investigation into the potential changes to crop physiology from vegetative growth to anthesis, fruit development and yield is required to elucidate the full potential of UV-C treatment on tomato. In addition, research into the molecular mechanisms underpinning disease control and biostimulation should also be undertaken.

\section{Acknowledgements}

The study was financed by the Agriculture and Horticulture Development Board's Horticulture Department (AHDB Horticulture), Loughborough University and King Saud University. All research was carried out at the University of Nottingham's Division of Plant and Crop Sciences.

This article is protected by copyright. All rights reserved. 


\section{References}

Aboul Fotouh, M.M, Moawad, F.G., El-Naggar, H.A., Tag El-Din, M.A. \& Sharaf Eldeen H.A., (2014). Influence of Seed Treatment with UV-C on Saline Stress Tolerance in Green Beans (Phaseolus vulgaris L.). The Journal of Biological Chemistry, 9, pp.391-414.

Beyers, T., Vos, C., Aerts, R., Heyens, K., Vogels L., Seels, B., Hofte, M., Cammue B.P.A. \& de Coninck, B., (2014). Resistance against Botrytis cinerea in Smooth Leaf Pruning Wounds of Tomato Does Not Depend on Major Disease Signalling Pathways. Plant Pathology, 63, pp.165-173

Borges, A.V., Saraiva, R.M. \& Maffia, L.A. (2014). Key Factors to Inoculate Botrytis cinerea in Tomato Plants. Summa Phytopathologica, 40, pp.221-225.

Brown, J.E., Lu, T. Y., Stevens, C., Khan, V.A., Lu, J.Y., Wilson, C.L., Collins, D.J., Wilson, M.A., Igwegbe, E.C.K., Chalutz, E. \& Droby, S., (2001). The Effect of Low Dose Ultraviolet Light-C Seed Treatment on Induced Resistance in Cabbage to Black Rot. Crop Protection, 20, pp. 873-883.

Charles, M.T., Mercier, J., Makhlouf, J., \& Arul, J. (2008a). Physiological Basis of UV-C Induced Resistance to Botrytis cinerea in Tomato Fruit. I. Role of Pre- and Post-Challenge Accumulation of the Phytoalexin-Rishitin. Postharvest Biology and Technology, 47, pp.1020.

Charles, M.T., Goulet, A., \& Arul, J. (2008b). Physiological Basis of UV-C Induced Resistance to Botrytis cinerea in tomato fruit. IV. Biochemical Modification of Structural Barriers.

Postharvest Biology and Technology, 47, pp.41-53.

Coolbear, P., Francis, A. \& Grierson, D., (1984). The Effect of Low Temperature Pre-Sowing Treatment on the Germination Performance and Membrane Integrity of Artificially Aged Tomato Seeds. Journal of Experimental Botany, 35, pp.1609-1617.

This article is protected by copyright. All rights reserved. 
Costa, L., Vicente, A.R., Civello, P.M., Chaves, A.R. \& Martinez, G.A., (2006). UV-C treatment delays postharvest senescence in broccoli florets. Postharvest Biology and Technology, 39, pp.204-210.

D’Hallewin, G., Schirra, M., Manueddu, E., Piga, A. \& Ben-Yehoshua, (1999). Scoparone and Scopoletin Accumulation and Ultraviolet-C Induced Resistance to Postharvest Decay in Oranges as Influences by Harvest Date. Journal of the American Society for Horticultural Science, 124, pp.702-707.

D’Hallewin, G., Schirra, M., Pala, M. \& Ben-Yehoshua, (2000). Ultraviolet C Irradiation at 0.5 $\mathrm{kJ} / \mathrm{m}-2$ Reduces Decay without Causing Damage or Affecting Postharvest Quality of Star Ruby Grapefruit (C. paradisi Macf.). Journal of Agricultural and Food Chemistry, 48, pp.4571-4575.

Eghball, B., \& Maeanville, J.W. (1993). Root Development and Nitrogen Influx of Corn Genotypes Grown Under Combined Drought and Nitrogen Stress. Agronomy Journal, 85, pp.147-152.

FAOSTAT, (2018). Production Database. The Food and Agriculture Organisation of the United Nations Statistics Division. [Online] < http://www.fao.org/faostat/en > [Accessed 21/02/2018].

Hamid, N. \& Javvaid, F., (2011). Influence of Seed Pre-treatment by UV-A and UV-C Radiation on Germination and Growth of Mung Beans. Pakistan Journal of Chemistry, 1, pp.164-167.

Jeger, M.J. \& Viljanen-Rollinson, S.L.H., (2001). The Use of the Area Under the DiseaseProgression Curve (AUDPC) to Assess Quantitative Disease Resistance in Crop Cultivars. Theoretical and Applied Genetics, 102, pp.32-44.

Kasim, R. \& Kasim, M.U. (2012). UV-C Treatments on Fresh-Cut Garden Cress (Lepidum sativum L.) Enhanced Chlorophyll Content and Prevent Leaf Yellowing. World Applied Sciences Journal. 17, 509-515.

This article is protected by copyright. All rights reserved. 
Kharb, R.P.S., Lather, B.P.S., Deswal, D.P., (1994). Prediction of field emergence through heritability and genetic advance of vigour parameters. Seed Science and Technology, 22, pp.461-466.

McPhearson, M. (2015). Challenges in the Control of Botrytis in Horticultural Crops. Crop Diseases - are we Losing control? The $2^{\text {nd }}$ Annual Diseases Review of the British Crop Production Council, NIAB Cambridge, $3^{\text {rd }}$ December.

Monk, C., (1966). Ecological Importance of Root/Shoot Ratios. Torrey Botanical Society, 93, pp.402-406

Neelamegam, R. \& Sutha, T., (2015). UV-C Irradiation Effect on Seed Germination, Seedling Growth and Productivity or Groundnut (Arachis hypogaea L.) International Journal of Current Microbiology and Applied Science, 4, pp.430-443.

Nirmaladevi, D., Venkataramana, M., Srivastava, R.K., Uppalapati, S.R., Gupta, V.K., YliMattila, T., Tsui, K.M.C., Srinivas, C., Niranjana, S.R. \& Chandra, N.S. (2016). Molecular Phylogeny, Pathogenicity and Toxigenicity of Fusarium oxysporum f.sp. lycopersici. Nature: Scientific Reports, 6:21367, DOI: 10.1038/srep21367

Ouhibi, C., Attia, H., Rebah, F., Msilini, N., Chebbi, M., Aarrouf, J., Urban, L. \& Lachaal, M. (2014). Salt Stress Mitigation by Seed Priming with UV-C in Lettuce Plants: Growth, Antioxidant Activity and Phenolic Compounds. Plant Physiology and Biochemistry, 83 pp.126-133.

Parke, J. L. \& Grau, C. R. (1993). Methods for Research on Soilborne Phytopathogenic Fungi. Aphanomyces. (Eds. Singleton, L.L., Mihail, J.D. \& Rush, C.M.). APS Press, St. Paul, MN, USA.

Pongprasert, N., Sekozawa, Y., Sugaya, S. \& Gemma, H. (2011). The Role and Mode of Action of UV-C Hormesis in Reducing Cellular Oxidative Stress and the Consequential Chilling Injury of Banana Fruit Peel. International Food Research Journal, 18, pp.741-749. 
Poorter, H. \& Ryser, P., (2015). The Limits to Leaf and Root Plasticity: What is so Special About Specific Root Length. New Phytologist, 206, pp.1188-1190.

Ranal, M.A., de Santana, D.G., Ferreira, W.R. and Mendes-Rodrigues, C., (2009). Calculating Germination Measurements and Organizing Spreadsheets. Revista Brasileira de Botanica, 32, pp.849-855.

Ranganna, B., Kushalappa, a. C. \& Raghavan, G.S.V. (1997). Ultraviolet Irradiance to Control Dry Rot and Soft Rot of Potato in Storage. Canadian Journal of Plant Pathology, 19, pp.3035.

Reis, A. \& Boiteux, L.S. (2007). Outbreak of Fusarium oxysporum f.sp. lycopersici race 3 in Commercial Fresh-Market Tomato Fields in Rio de Janeiro State, Brazil. Horticultura Brasileira, 25, pp. 451-454.

Ribeiro, C., Canada, J., \& Alvarenga, B. (2012). Prospects of UV Radiation for Application in Postharvest Technology. Emirates Journal of Food and Agriculture, 24, pp.586-597. Ron, M., Dorrity, M.W., de Lucas, M., Toal, T., Hernandez, R.I., Little, S.A., Maloof, J.N., Kliebenstein, D.J. \& Brady, S.M. (2013). Identification of Novel Loci Regulating Interspecific Variation in Root Morphology and Cellular Development in Tomato. Plant Physiology, 162, pp.755-768.

Ruijter, J.M., Thygsen, H.H., Schoneveld, O.J.L.M., Das, A.T., Berkhout, B. \& Lamers, W.H., (2006). Factor Correction as a Tool to Eliminate Between-Session Variation in Replicate Experiments: Application to Molecular Biology and Retrovirology. Retrovirology, 3 [online] doi:10.1186/1742-4690-3-2

Scott, G., Rupar, M., Fletcher, A.G.D., Dickinson, M. \& Shama, G. (2017). A Comparison of Low Intensity UV-C and High Intensity Pulsed Polychromatic Sources as Elicitors of Hormesis in Tomato Fruit. Postharvest Biology and Technology, 125, pp.52-58.

This article is protected by copyright. All rights reserved. 
Scott, G., Dickinson, M., Shama, G. \& Rupar, M. (2018). A Comparison of the Molecular Mechanisms Underpinning High-Intensity, Pulsed Polychromatic Light and Low-Intensity UVC Hormesis in Tomato Fruit. Postharvest Biology and Technology, 137, pp.46-55.

Shama, G. \& Alderson, P. (2005). UV Hormesis in Fruits: A Concept Ripe for Commercialisation. Trends in Food Science and Technology, 16, pp.128-136.

Siddiqui, A., Dawar, S., Zaki, M.J. \& Hamiid., (2011). Role of Ultraviolet (UV-C) Radiation in the Control of Root Infecting Fungi on Groundnut and Mungbean. Pakistan Journal of Botany, 43, pp.2221-2224.

Turtoi, M. (2013). Ultraviolet Light Treatment of Fresh Fruits and Vegetables Surface: A Review. Journal of Agroalimentary Processes and Technologies, 19, pp.325-337.

Urban, L., Charles, F., de Miranda, M.R.A. \& Aarrouf, J. (2016). Understanding the Physiological Effects of UV-C Light and Exploiting its Agronomic Potential Before and After Harvest. Plant Physiology and Biochemistry, 105, pp.1-11.

Walker-Simmons, M., (1987). ABA Levels and Sensitivity in Developing Wheat Embryos of Sprouting Resistance and Susceptible Cultivars. Plant Physiology, 84, pp.61-66.

This article is protected by copyright. All rights reserved. 
Table 1. Equations for growth metrics

\begin{tabular}{|c|c|c|}
\hline Measure & Equation & Reference \\
\hline Root mass fraction & Root mass $\div$ total plant mass & Poorter \& Ryser 2015 \\
\hline Stem mass fraction & Stem mass $\div$ total plant mass & Poorter \& Ryser 2015 \\
\hline Root:shoot ratio & Root mass $\div$ Shoot mass & Monk, 1966 \\
\hline Seedling vigour index II & $\begin{array}{c}\text { Germination percentage } \times \text { mean dry } \\
\text { weight }\end{array}$ & Kharb et al., 1994 \\
\hline
\end{tabular}

Table 2. Mean germination metrics of tomato seeds (cv. Shirley) following UV-C treatment

\begin{tabular}{cccccc}
\hline $\begin{array}{c}\text { UV-C dose } \\
\left(\mathbf{k J} / \mathbf{m}^{\mathbf{2}}\right)\end{array}$ & $\begin{array}{c}\text { Total } \\
\text { germination } \\
\mathbf{( \% )}\end{array}$ & $\begin{array}{c}\text { Germination } \\
\text { index }\end{array}$ & $\mathbf{T}_{\mathbf{5 0}}$ & Z-index & $\begin{array}{c}\text { Seedling vigour } \\
\text { index-II }\end{array}$ \\
\hline 0 & $93.65 \pm 2.75$ & $66.33 \pm 10.97$ & $4.23 \pm 0.87$ & $0.21 \pm 0.04$ & $335.87 \pm 39.61$ \\
\hline 4 & $87.30 \pm 7.27$ & $63.33 \pm 1.15$ & $4.32 \pm 0.08$ & $0.21 \pm 0.03$ & $339.07 \pm 80.40$ \\
\hline 8 & $95.24 \pm 0.00$ & $79.00 \pm 3.00$ & $3.41 \pm 0.36$ & $0.25 \pm 0.05$ & $386.51 \pm 73.71$ \\
\hline 12 & $95.24 \pm 4.76$ & $68.33 \pm 4.04$ & $4.13 \pm 0.23$ & $0.19 \pm 0.01$ & $377.39 \pm 78.10$ \\
\hline
\end{tabular}

Means are accompanied by \pm 1 S.E.M. $\mathrm{N}=63$.
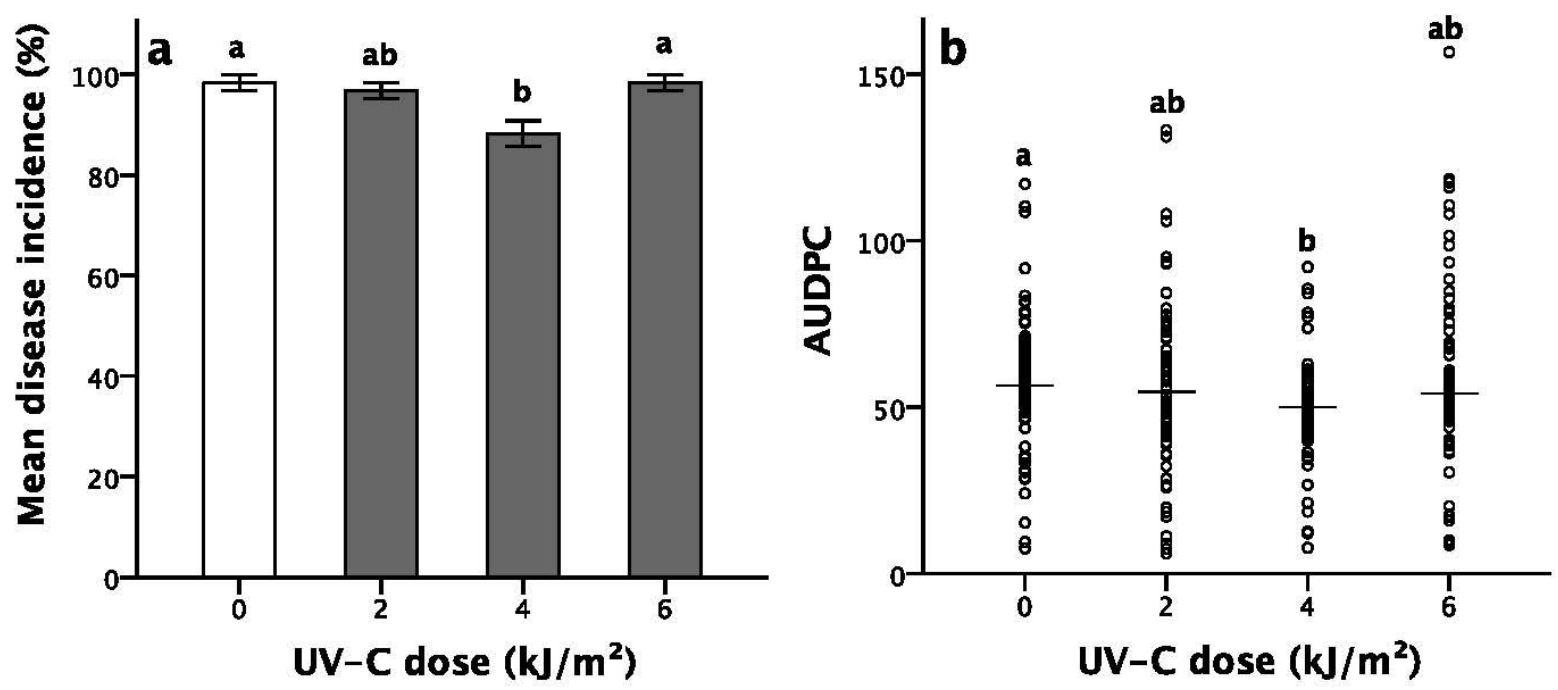

This article is protected by copyright. All rights reserved. 

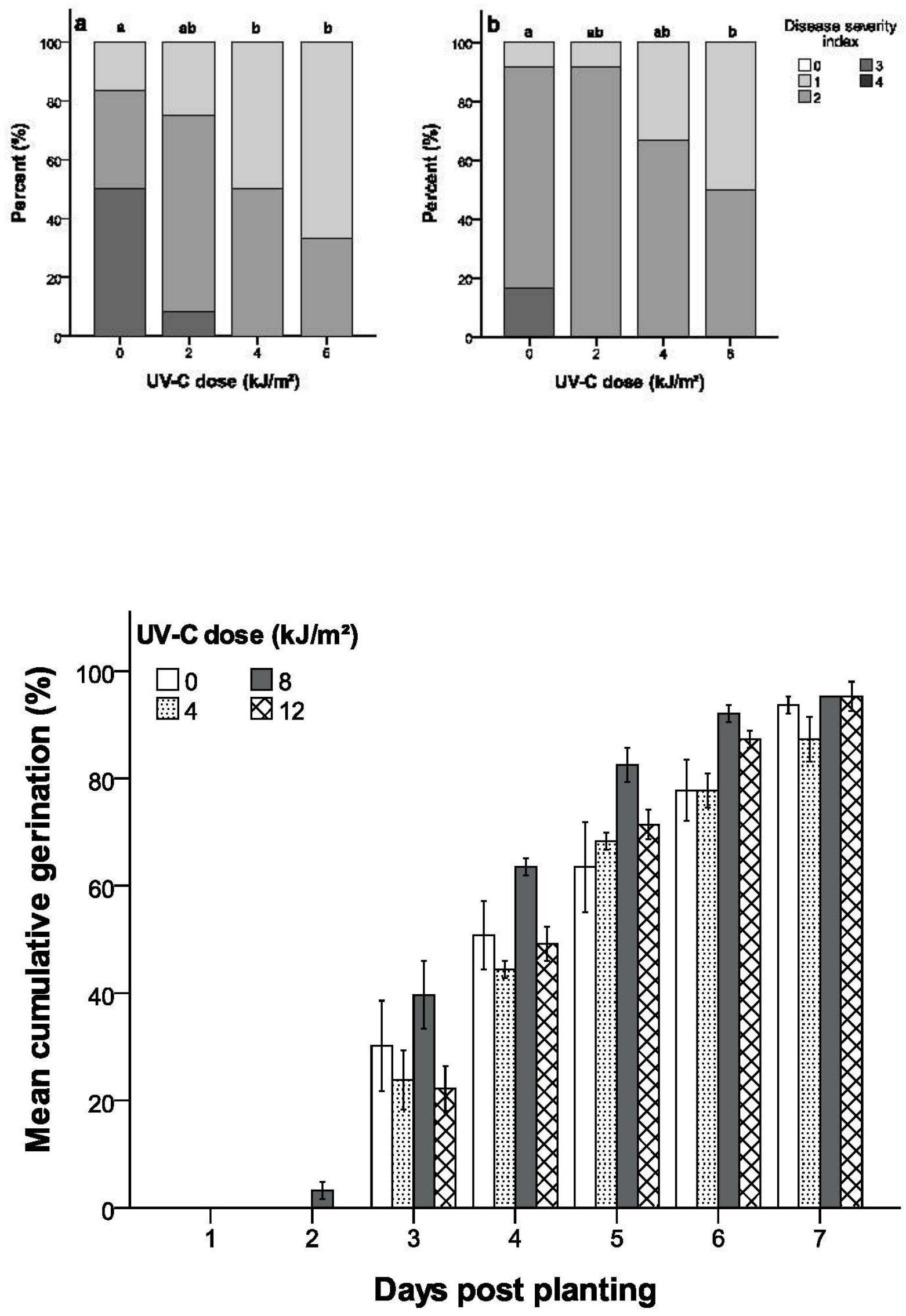

This article is protected by copyright. All rights reserved. 

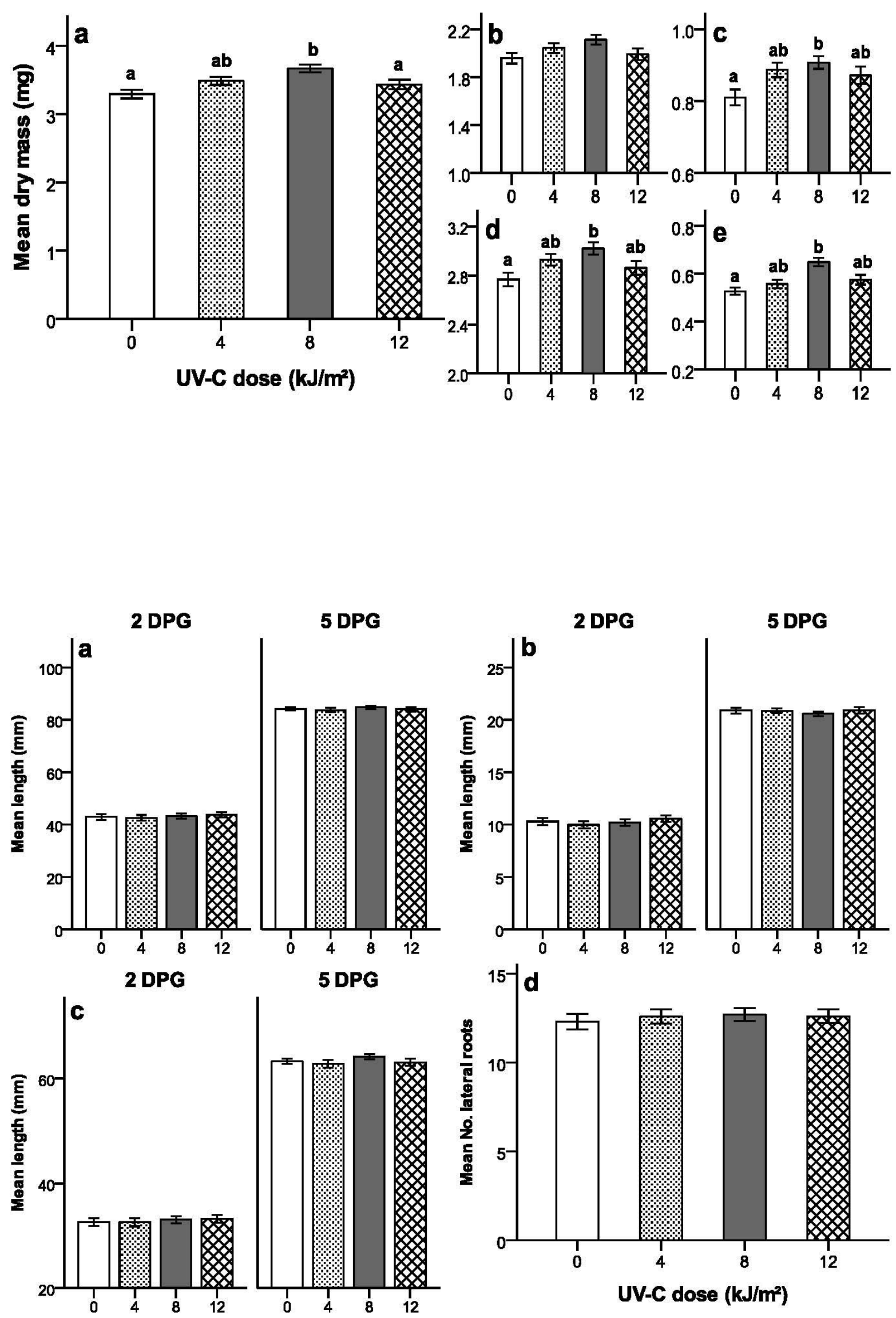

This article is protected by copyright. All rights reserved. 

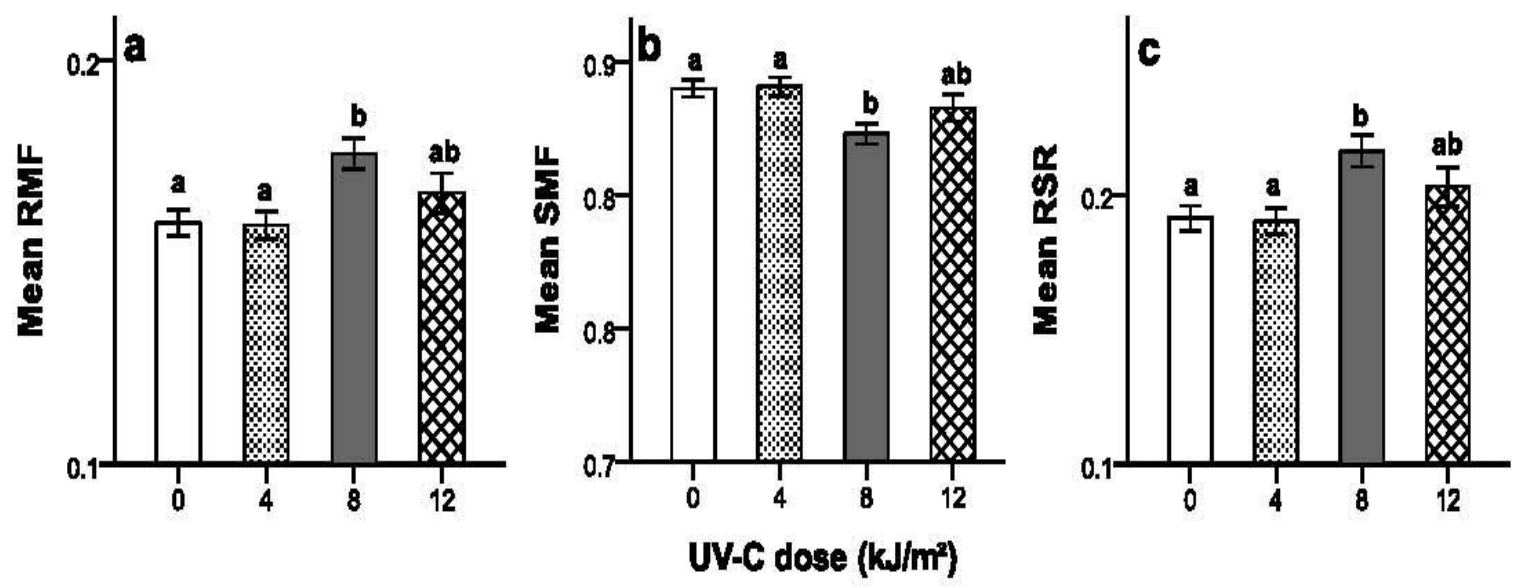

This article is protected by copyright. All rights reserved. 